\title{
Effect of Nitrogen Content on the Microstructure and Mechanical Properties of Ti-Mo-N Coating Films
}

\begin{abstract}
SHOKO KOMIYAMA, YUJI SUTOU, and JUNICHI KOIKE
Effects of nitrogen content on the microstructure, hardness, and friction coefficient of Ti-Mo-N coating films were investigated. Ti-Mo-N films were deposited onto an AISI304 stainless steel substrate by reactive r.f. sputtering in the mixture of argon and nitrogen gases with various gas flow rates. The hardness and friction coefficients were measured by nanoindentation and ball-on-disk testing systems, respectively. The hardness of the Ti-Mo-N films increased with increasing a nitrogen gas flow rate $\left(f_{\mathrm{N}_{2}}\right)$ and showed a maximum hardness of about $30 \mathrm{GPa}$ at a $f_{\mathrm{N}_{2}}=0.3 \mathrm{ccm}$. On the one hand, the films deposited at $f_{\mathrm{N}_{2}} \geq 1.0 \mathrm{ccm}$ showed a constant hardness value of approximately $25 \mathrm{GPa}$. On the other hand, the friction coefficient of the Ti-Mo-N film decreased with increasing $\mathrm{N}$ content and was 0.44 in the film deposited at $f_{\mathrm{N}_{2}}=2.0 \mathrm{ccm}$.
\end{abstract}

DOI: $10.1007 / \mathrm{s} 11661-010-0522-\mathrm{x}$

(C) The Author(s) 2010. This article is published with open access at Springerlink.com

\section{INTRODUCTION}

THE TiN hard-coating films have been used for various industrial applications such as cutting tools, medical devices, and mold lubricant materials because of their high hardness of approximately 20 to $28 \mathrm{GPa}^{[1-3]}$ and high oxidation resistance. For the subsequent enhancement of their functions, the simultaneous improvement of hardness, friction coefficient, and wear resistance is strongly required. In this aspect, many attempts have been made to improve these properties, mainly by alloying TiN coating films. It has been reported that Ti-Al-N coating films show a high hardness because of the solution hardening effect with an excellent oxidation resistance. ${ }^{[3-5]}$ Ti-Si-N and Ti-B-N coating films show an extremely high hardness because of the formation of the nanocomposite structure of amorphous-Si-N/nanocrystalline-TiN and amorphous-B-N or Ti-B/nanocrystalline-TiN, respectively. ${ }^{[6-1]]}$ Although these TiN-based coating films show a high hardness (30 to $60 \mathrm{GPa}^{[3,5-10]}$, their high friction coefficients $(0.6$ to $0.8^{[10,12,13]}$ ) leads to poor wear resistance.

Meanwhile, a low friction coefficient could be obtained with Mo-containing films. For example, Mo-containing $\mathrm{Cr}_{2} \mathrm{O}_{3}$ films showed a lower friction coefficient and wear rate than $\mathrm{Mo}$-free $\mathrm{Cr}_{2} \mathrm{O}_{3}$ films. ${ }^{[14]}$ Moreover, Mo-N coating films exhibited a lower friction coefficient and a shallower wear depth than TiN coating films. ${ }^{[15]}$ The constituent phases and the hardness of the Mo-N coating films strongly depended on $\mathrm{N}$ content. ${ }^{[16]}$ Recently, Yang et al. ${ }^{[17]}$ investigated the effects of Mo addition to Ti-N coating films. They reported that the increase of the Mo content in the Ti-Mo-N coating films

SHOKO KOMIYAMA, Graduate Student, YUJI SUTOU, Associate Professor, and JUNICHI KOIKE, Professor, are with Department of Materials Science, Graduate School of Engineering, Tohoku University, Aoba-yama 6-6-11, Sendai 980-8579, Japan. Contact e-mail: b0td5306@s.tohoku.ac.jp

Manuscript submitted February 24, 2010.

Article published online November 9, 2010 increased the hardness and decreased the friction coefficient. However, the effects of the nitrogen content have not been investigated. As reported in the Mo-N films, ${ }^{[16]}$ the nitrogen content is an important factor to control the microstructure and the mechanical properties of coating films. Therefore, in the current work, we investigated the effects of nitrogen content on the microstructure, hardness, and friction coefficient of the Ti-Mo-N coating films.

\section{EXPERIMENTAL PROCEDURE}

Ti-Mo-N films were deposited on mirror-polished plates of AISI 304 stainless steel by r.f. reactive magnetron sputtering at room temperature, using a $\mathrm{Ti}_{50} \mathrm{Mo}_{50}$ target ( 99.9 pct purity). To form nitrides, the mixture of argon and nitrogen gases was introduced under the condition where argon gas flow rate was fixed at $7.5 \mathrm{ccm}$ and nitrogen gas flow rate $\left(f_{\mathrm{N}_{2}}\right)$ was changed from $0 \mathrm{ccm}$ to $2.0 \mathrm{ccm}$. The r.f. power for sputtering deposition was $50 \mathrm{~W}$, and the substrate temperature during deposition was below $323 \mathrm{~K}\left(50{ }^{\circ} \mathrm{C}\right)$. The sputtering time was fixed at 2 hours. In the current study, a Ti-N film was deposited using a Ti target $(99.9$ pct purity) at $f_{\mathrm{N}_{2}}=0.5 \mathrm{ccm}$, where the sputtering time was fixed at 9 hours to obtain the film with thickness of more than $600 \mathrm{~nm}$. The sputtered film thickness was measured by a surface profilometer. The surface roughness $\left(R_{a}\right)$ of the films was measured by an atomic force microscope in a scan area of $100 \times 100 \mu \mathrm{m}$.

The constituent phases of the obtained Ti-Mo-N films were examined by X-ray diffraction (XRD) using $\mathrm{Cu}-\mathrm{K} \alpha$ radiation. The chemical composition of the films was measured by Auger electron spectroscopy. Ti, Mo, and $\mathrm{N}$ contents were determined quantitatively by a relative sensitivity coefficient method using Ti-50 at. pct $\mathrm{N}$ and Ti-5 at. pct Mo ( -5 at. pct Sn) as reference standards. The microstructure was observed by a transmission 
electron microscope (TEM). Cross-sectional TEM samples were prepared using a focused ion beam system.

The hardness was measured by a nanoindentation system (Hysitron Inc., Triboindenter, MN) using a Berkovich indenter. The load was controlled so that the contact depth was kept less than 10 pct of the film thickness. The friction coefficient was measured by a ball-on-disk testing system (FPR-2100; RHESCA Co., Ltd., Tokyo, Japan) at room temperature. The test was carried out under a load of 500 gf at a sliding speed of $75 \mathrm{~mm} /$ second. A tungsten carbide ball was used as a counterpart, and the total wear distance was $100 \mathrm{~m}$. The wear track on the film surface after boll-on-disk testing was observed by an optical microscope and a scanning electron microscope (SEM).

\section{RESULTS AND DISCUSSION}

\section{A. Chemical Composition and Constituent Phases}

Table I shows the thickness, the surface roughness, and the $\mathrm{Ti}, \mathrm{Mo}$, and $\mathrm{N}$ contents of the films deposited at $f_{\mathrm{N}_{2}}=0,0.2,0.3,0.5,1.0$, and $2.0 \mathrm{ccm}$ for 2 hours. The film thickness decreases with increasing $f_{\mathrm{N}_{2}}$ of more than $0.5 \mathrm{ccm}$. This is a result of the decrease in the sputtering rate with increasing $f_{\mathrm{N}_{2}}$ as reported in the case of TiN film. ${ }^{[18]}$ The surface roughness of the films is independent of $f_{\mathrm{N}_{2}}$ and very small, which indicates that the effects of surface roughness on mechanical property measurement are negligible. The $\mathrm{N}$ content increases with increasing $f_{\mathrm{N}_{2}}$ in the region of $f_{\mathrm{N}_{2}} \leq 0.5 \mathrm{ccm}$, and then it approached to a constant chemical composition $(\mathrm{N} \approx 42$ at. pct $)$ at $f_{\mathrm{N}_{2}}=0.5 \mathrm{ccm}$.

Figure 1 shows the XRD patterns of the films deposited at $f_{\mathrm{N}_{2}}=0,0.2,0.3,0.4,0.5,1.0$, and $2.0 \mathrm{ccm}$. The film deposited without nitrogen gas shows a basecentered cubic (bcc)-(Ti,Mo) phase pattern with a strong 110 preferential orientation. In the Ti-Mo-N film deposited at $f_{\mathrm{N}_{2}}=0.2 \mathrm{ccm}$, the position of the bcc(Ti,Mo) 110 peak is slightly shifted to a higher diffraction angle, and the peak width seems to be broadened. Moreover, the broad peak has a shoulder at the lower angle side. Because the lattice spacing of the bcc-(Ti,Mo) phase decreases with decreasing the Ti content, ${ }^{[19]}$ it is suggested that the shift of the peak position is caused by the decrease of the Ti content in the bcc-(Ti,Mo) phase. The shoulder peak is most likely a result of the

Table I. Film Thickness, Surface Roughness, and Ti, Mo, and N Contents of the Ti-Mo-N Films Deposited at Various Nitrogen Gas Flow Rates $f_{\mathrm{N}_{2}}$

\begin{tabular}{lccccc}
\hline & $\begin{array}{c}\text { Film } \\
\text { Thickness } \\
(\mathrm{nm})\end{array}$ & $\begin{array}{c}\text { Roughness, } \\
R_{a}(\mathrm{~nm})\end{array}$ & $\begin{array}{c}\text { Ti } \\
\text { (at. pct) }\end{array}$ & $\begin{array}{c}\text { Mo } \\
\text { (at. pct) }\end{array}$ & $\begin{array}{c}\mathrm{N} \\
\text { (at. pct) }\end{array}$ \\
\hline 0 & 1580 & 2.4 & - & - & - \\
0.2 & 1556 & 4.3 & 37.0 & 31.5 & 31.5 \\
0.3 & 1586 & 2.4 & 34.9 & 28.4 & 36.7 \\
0.5 & 1043 & 3.2 & 31.8 & 26.1 & 42.1 \\
1.0 & 738 & 4.2 & 31.1 & 26.8 & 42.1 \\
2.0 & 601 & 5.9 & 29.6 & 28.6 & 41.8 \\
\hline
\end{tabular}

formation of the $\varepsilon-\mathrm{Ti}_{2} \mathrm{~N}$ phase by the inflow of nitrogen gas. The $\varepsilon-\mathrm{Ti}_{2} \mathrm{~N}$ phase formation was also reported in a r.f. sputtered TiN film with a low $\mathrm{N}$ content of approximately 30 at. pet N. ${ }^{[20]}$ The XRD pattern of the film deposited at $f_{\mathrm{N}_{2}}=0.3 \mathrm{ccm}$ indicates the formation of the $\delta$-(Ti,Mo)N phase as a main phase. As the $f_{\mathrm{N}_{2}}$ increases from $0.3 \mathrm{ccm}$ to $2.0 \mathrm{ccm}$, the $\delta-(\mathrm{Ti}, \mathrm{Mo}) \mathrm{N}$ peak positions are shifted to lower diffraction angles. It was reported in a $\delta$-TiN film that the lattice spacing increases with increasing $\mathrm{N}$ content ${ }^{[20]}$ and that the magnitude of compressive residual stress increases with increasing nitrogen partial pressure during sputtering under the pressure condition of $\mathrm{P}_{\mathrm{N}_{2}} / \mathrm{P}_{\mathrm{Ar}}>0.03^{[21]}$. In the current study, the partial pressure ratio $\mathrm{P}_{\mathrm{N}_{2}} / \mathrm{P}_{\mathrm{Ar}}$ at $f_{\mathrm{N}_{2}}=0.3 \mathrm{ccm}$ is estimated to be approximately 0.04 . Therefore, in the region of $0.3 \mathrm{ccm} \leq f_{\mathrm{N}_{2}} \leq 0.5 \mathrm{ccm}$, the shift of the XRD peak positions of the $\delta$-( Ti, Mo) N is considered to be not only a result of the expansion of the lattice spacing with increasing the $\mathrm{N}$ content, but also a result of to the increase of the compressive residual stress with increasing the $f_{\mathrm{N}_{2}}$. The films deposited at $f_{\mathrm{N}_{2}}=0.5 \mathrm{ccm}$ have almost the same $\mathrm{N}$ content. Therefore, the shift of the XRD peak positions in the films at $f_{\mathrm{N}_{2}}>0.5 \mathrm{ccm}$ is only caused by the increase of the compressive residual stress.

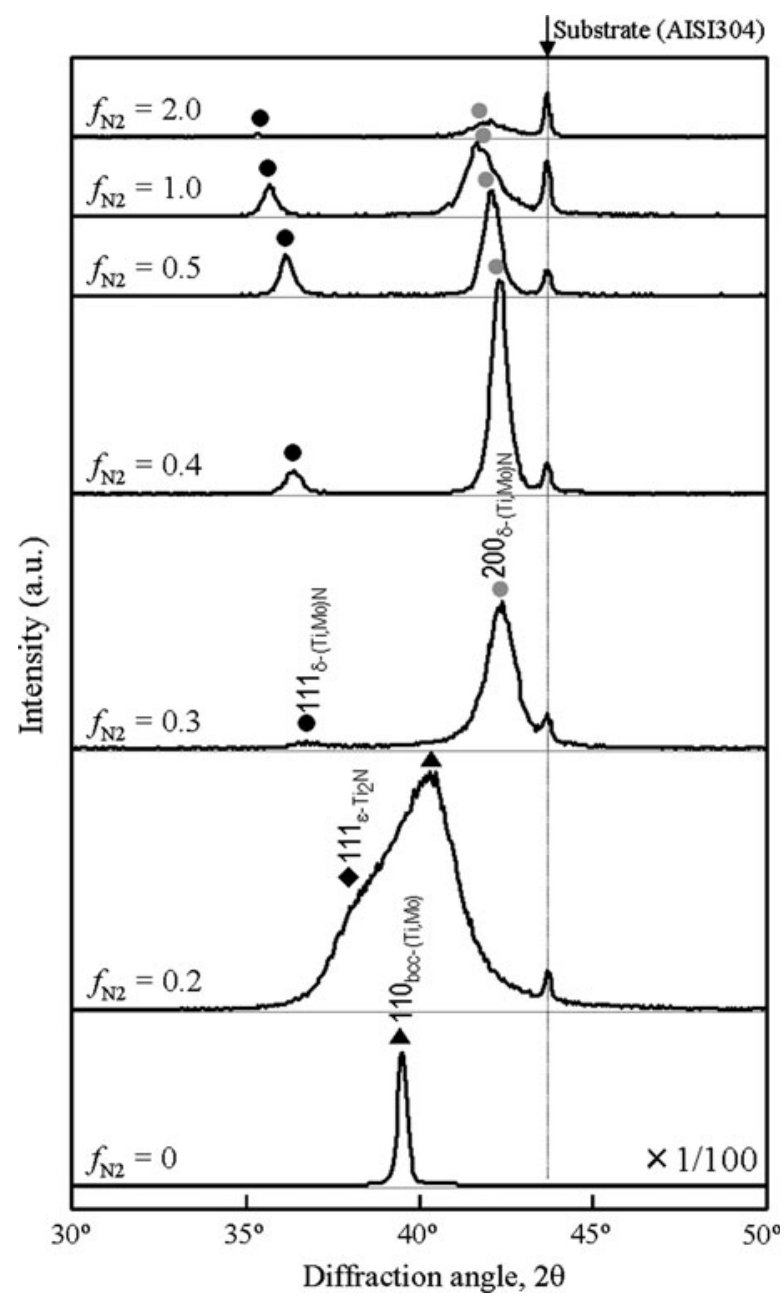

Fig. 1-XRD patterns of the Ti-Mo-N films deposited at various nitrogen gas flow rates $f_{\mathrm{N}_{2}}$. 


\section{B. Effect of $f_{\mathrm{N}_{2}}$ on Hardness of Ti-Mo-N Films}

Figure 2 shows the plot of hardness as a function of $f_{\mathrm{N}_{2}}$. The hardness drastically increases with increasing $f_{\mathrm{N}_{2}}$ and reaches a maximum hardness of about $30 \mathrm{GPa}$ at $f_{\mathrm{N}_{2}}=0.3 \mathrm{ccm}$. By a subsequent increase of $f_{\mathrm{N}_{2}}$, the hardness slightly decreases and becomes almost a constant value of about $25 \mathrm{GPa}$ in the region of $f_{\mathrm{N}_{2}} \geq 1.0 \mathrm{ccm}$. Ti-N film deposited at $f_{\mathrm{N}_{2}}=0.5 \mathrm{ccm}$ showed the hardness of approximately $28 \mathrm{GPa}$, which is almost the same value as that of the Ti-Mo-N film deposited at $f_{\mathrm{N}_{2}}=0.5 \mathrm{ccm}$.

Figure 3 shows the cross-sectional TEM bright-field images of Ti-Mo-N films deposited at $f_{\mathrm{N}_{2}}=0.2$ (Figure 3(a)), 0.3 (Figure 3(b)), and $1.0 \mathrm{ccm}$ (Figure 3(c)). All films show a columnar grain structure. The grain size becomes coarser as the $f_{\mathrm{N}_{2}}$ increases. The film at $f_{\mathrm{N}_{2}}=0.2$ has very fine grain size of approximately $10 \mathrm{~nm}$. The grain size of the film at $f_{\mathrm{N}_{2}}=0.3 \mathrm{ccm}$ is less than $50 \mathrm{~nm}$, whereas that of the film at $f_{\mathrm{N}_{2}}=1.0 \mathrm{ccm}$ is much coarser and is approximately $100 \mathrm{~nm}$. From the XRD result, the film at $f_{\mathrm{N}_{2}}=0.2 \mathrm{ccm}$ has a secondary $\varepsilon-\mathrm{Ti}_{2} \mathrm{~N}$ phase in addition to a main bcc(Ti,Mo) phase. The presence of the secondary phase is likely to cause the grain refinement. Although the $\varepsilon-\mathrm{Ti}_{2} \mathrm{~N}$ phase is detected in the XRD spectra, it is difficult to identify in the TEM bright-field image of the film at $f_{\mathrm{N}_{2}}=0.2 \mathrm{ccm}$ because of the fine and complicated microstructure. The initial drastic hardening is a consequence of the formation of the nitrides and the finegrain structure. The film at $f_{\mathrm{N}_{2}}=0.3 \mathrm{ccm}$ showed a maximum hardness of approximately $30 \mathrm{GPa}$. Vaz et al. ${ }^{[18]}$ reported a similar relation between the hardness and the $\mathrm{N}$ content in TiN film. They reported that the TiN film with a lower $\mathrm{N}$ content of approximately 30 at. pct exhibited a maximum hardness, which was caused by the grain refinement of $\delta$-TiN phase because of the presence of an $\varepsilon-\mathrm{Ti}_{2} \mathrm{~N}$ phase. In the current study, although a clear crystalline peak is not observed except the $\delta$-(Ti,Mo)N peaks in the film deposited at $f_{\mathrm{N}_{2}}=0.3 \mathrm{ccm}$ (Figure 1), the presence of the $\varepsilon-\mathrm{Ti}_{2} \mathrm{~N}$ phase may be related to the grain refinement of the $\delta$-(Ti,Mo)N phase.

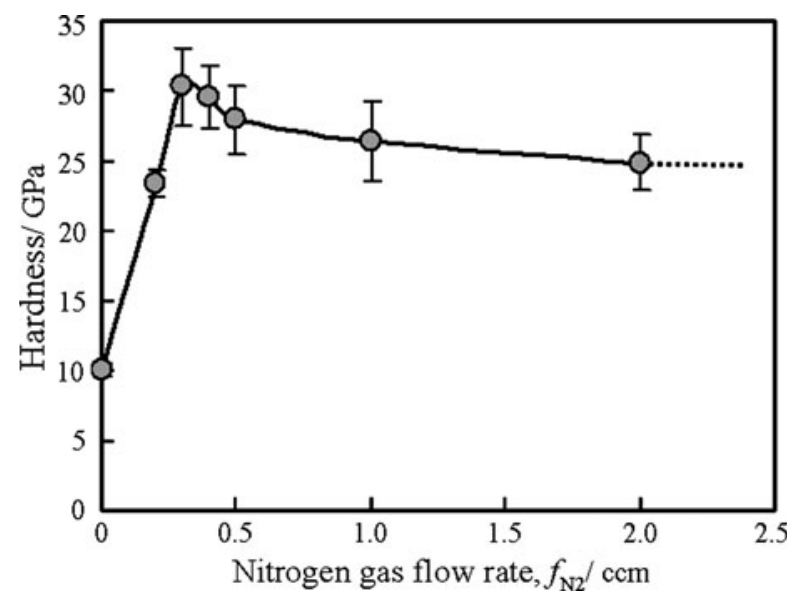

Fig. 2-The relation between nitrogen gas flow rate $\left(f_{\mathrm{N}_{2}}\right)$ and hardness in the Ti-Mo-N film.

\section{Effect of $f_{\mathrm{N}_{2}}$ on Wear Property of Ti-Mo-N Films}

Figure 4 shows the friction coefficient as a function of sliding distance in the films deposited at $f_{\mathrm{N}_{2}}=$ 0.3 and $2.0 \mathrm{ccm}$. In the both films, the friction coefficient does not vary much with distance. The friction coefficient of the film at $f_{\mathrm{N}_{2}}=2.0$ is lower than that at $f_{\mathrm{N}_{2}}=0.3$. Note that the data of the film deposited at

(a) $f_{\mathrm{N} 2}=0.2 \mathrm{ccm}$

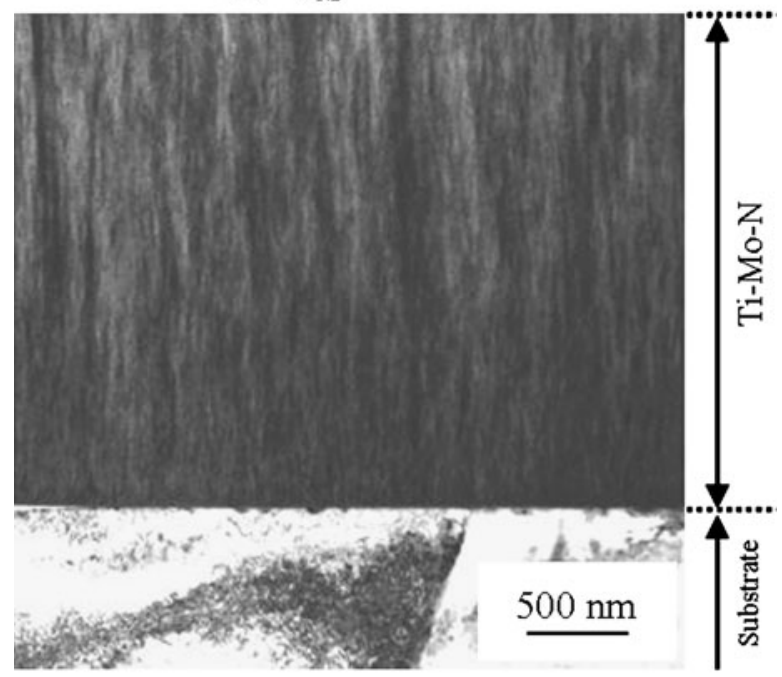

(b) $f_{\mathrm{N} 2}=0.3 \mathrm{ccm}$

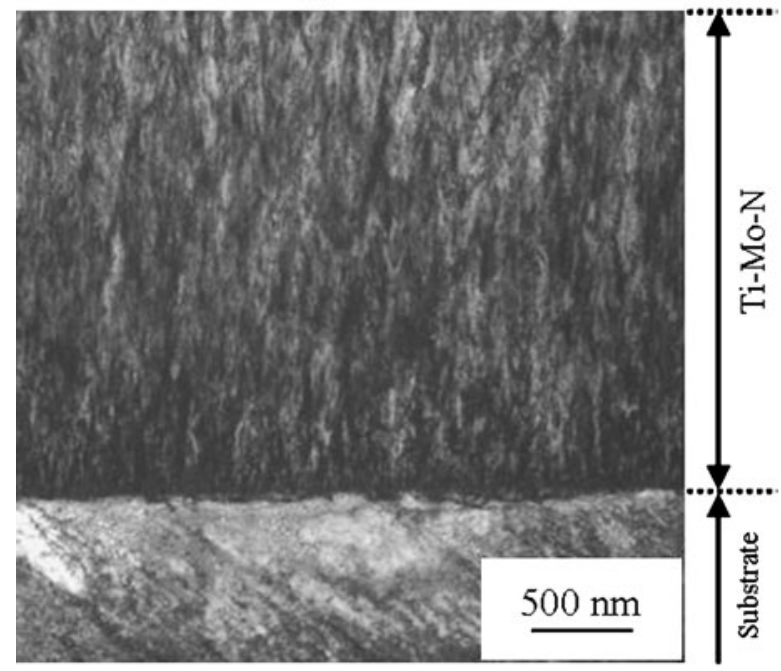

(c) $f_{\mathrm{N} 2}=1.0 \mathrm{ccm}$

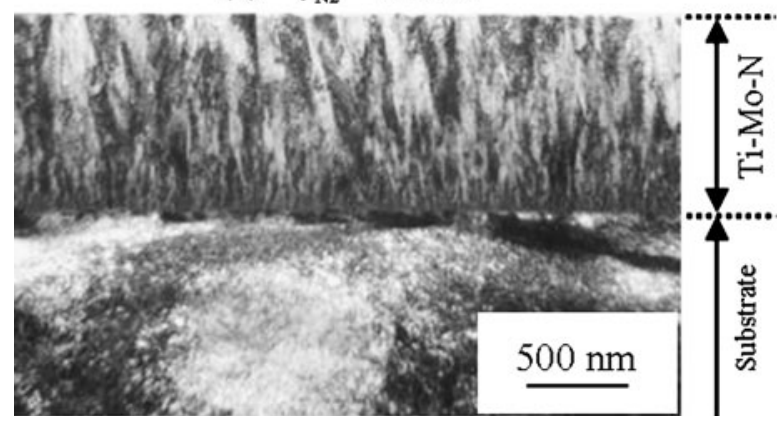

Fig. 3-Cross-sectional TEM bright-field images of the Ti-Mo-N films at $(a) f_{\mathrm{N}_{2}}=0.2,(b) 0.3$, and $(c) 1.0 \mathrm{ccm}$. 


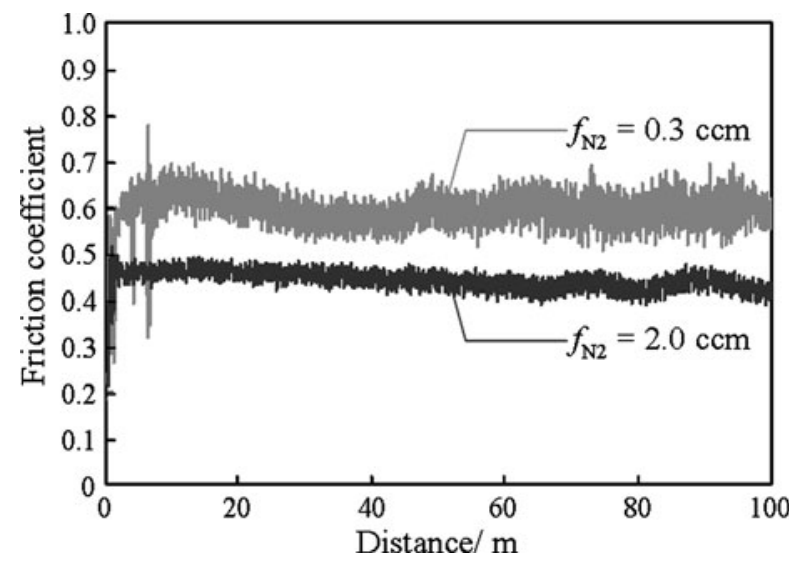

Fig. 4-Friction coefficient as a function of sliding distance in the Ti-Mo-N films at $f_{\mathrm{N}_{2}}=0.3$ and $2.0 \mathrm{ccm}$.

Table II. Friction Coefficient of the Ti-Mo-N Films Deposited at Various Nitrogen Gas Flow Rates $f_{\mathrm{N}_{2}}$

\begin{tabular}{lcc}
\hline$f_{\mathrm{N}_{2}}(\mathrm{ccm})$ & Friction Coefficient & Wear Track Observation \\
\hline 0.2 & N/A & Delamination \\
0.3 & 0.59 & Delamination \\
1.0 & 0.53 & No delamination \\
2.0 & 0.44 & No delamination \\
TiN & N/A & Delamination \\
\hline
\end{tabular}

$f_{\mathrm{N}_{2}}=0.3$ are scattered in the initial part of the data. Table II summarizes the average values of the friction coefficients measured over a distance of $100 \mathrm{~m}$ for Ti-Mo-N and Ti-N films. The friction coefficient of the Ti-Mo-N film at $f_{\mathrm{N}_{2}}=0.2 \mathrm{ccm}$ is not included because the film was delaminated from the substrate before the wear distance reached $5 \mathrm{~m}$. As the $f_{\mathrm{N}_{2}}$ increases, the friction coefficients are found to decrease. Meanwhile, the TiN film obtained in the present study was delaminated rapidly from the AISI304 substrate. The Ti-Mo-N film at $f_{\mathrm{N}_{2}}=2.0 \mathrm{ccm}$ shows a low friction coefficient of 0.44 , which is lower than the values of Ti-N (0.5 to $0.6),{ }^{[12]} \mathrm{Ti}-\mathrm{Al}-\mathrm{N}(0.6$ to 0.8$),{ }^{[12]} \mathrm{Ti}-\mathrm{Si}-\mathrm{N}(0.7$ to 0.8$),{ }^{[13]}$ and Ti-B-N films (0.6 to 0.9$) \cdot{ }^{[10]}$

Figure 5 shows the optical micrographs of wear track on the surface of the films deposited at $f_{\mathrm{N}_{2}}=0.3$ (Figure 5(a)) and $2.0 \mathrm{ccm}$ (Figure 5(b)). On the one hand, in the Ti-Mo-N film at $f_{\mathrm{N}_{2}}=0.3 \mathrm{ccm}$, delamination was observed everywhere along the wear track (Figure 5(a)), which causes the data scattering of the friction coefficient shown in Figure 4. On the other hand, there was no delamination in the Ti-Mo-N film at $f_{\mathrm{N}_{2}}=2.0 \mathrm{ccm}$ after testing, and the width of the wear track became narrower as shown in Figure 5(b). A surface observation using an optical microscope suggests that the main wear mechanisms of the Ti-Mo-N films at $f_{\mathrm{N}_{2}}=0.2$ and $0.3 \mathrm{ccm}$ containing a lower nitrogen content are abrasive wear and delamination, which lead to poor wear properties. Similar tendencies at a low $\mathrm{N}$ content have been reported in $\mathrm{W}-\mathrm{N}^{[22]}$ and Ti-Al- $\mathrm{N}^{[23]}$ films. In the W-N film with a low $\mathrm{N}$ content, even if the hardness of the film was high, the friction coefficient and

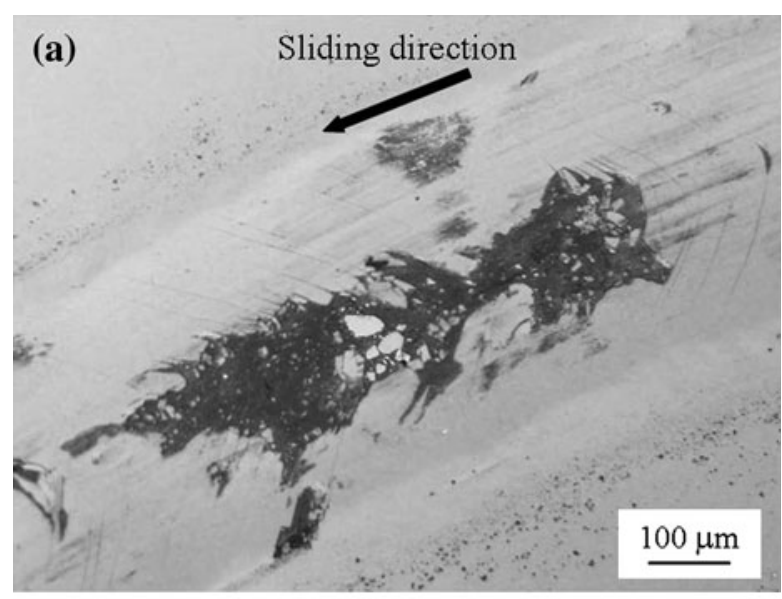

(b)

Sliding direction

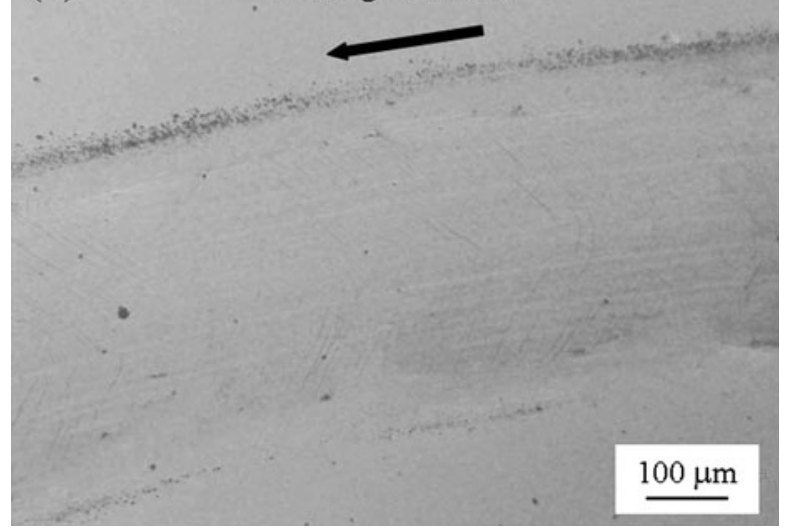

Fig. 5-A wear track observed by an optical microscope in the Ti-Mo-N films at $(a) f_{\mathrm{N}_{2}}=0.3$ and $(b) 2.0 \mathrm{ccm}$.

the wear rate were high. This finding was attributed to the formation of large wear debris containing W-N particles larger than $5 \mu \mathrm{m}$. Similar to the $\mathrm{W}-\mathrm{N}$ film with a low $\mathrm{N}$ content, the current Ti-Mo-N films with the low $\mathrm{N}$ content of $f_{\mathrm{N}_{2}}=0.2$ and $0.3 \mathrm{ccm}$ also showed large wear debris in Figure 5(a), which caused abrasive wear with the large friction coefficient.

In contrast, the Ti-Mo-N films at $f_{\mathrm{N}_{2}}=1.0$ and $2.0 \mathrm{ccm}$ have no such large wear debris. According to Yang et al., ${ }^{[17]}$ the friction coefficient of Ti-Mo-N film with a high $\mathrm{N}$ content of approximately 40 at. pct decreased with an increasing Mo content. They claimed that the friction coefficient was reduced by the formation of very small lubricious particles of molybdenum oxide on the wear track surface in dry sliding wear conditions. ${ }^{[17]}$ Moreover, Polcar et al. ${ }^{[22]}$ suggested that W-N films with a high nitrogen content showed a rapid production of small tungsten trioxide particles, which was caused by the liberation of nitrogen during tribooxidation. The fine oxide particles were suggested to cause a lower friction coefficient. ${ }^{[22]}$ In our Ti-Mo-N film case, the small particles were also observed in the film with a high $\mathrm{N}$ content. Figure 6 shows the SEM micrograph of wear track on the surface of the film deposited at $f_{\mathrm{N}_{2}}=2.0 \mathrm{ccm}$. Tiny needle-like particles are observed on the wear track, and are considered to be composed of a molybdenum oxide. Therefore, it is 


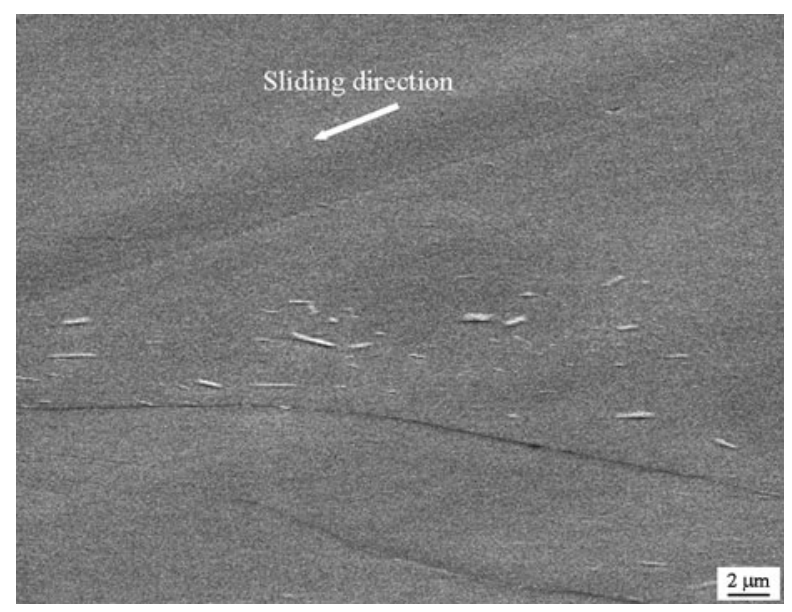

Fig. 6-SEM micrograph of the wear track on the surface of the Ti-Mo-N film at $f_{\mathrm{N}_{2}}=2.0 \mathrm{ccm}$.

suggested that a high $\mathrm{N}$ content is essential to obtain fine luburicious oxide particles and to have a good wear property in the Ti-Mo-N film.

Additionally, it is noted that the $\mathrm{N}$ content is almost the same in the two Ti-Mo-N films deposited at $f_{\mathrm{N}_{2}}=1.0$ and $2.0 \mathrm{ccm}$, yet the film deposited at $f_{\mathrm{N}_{2}}=2.0 \mathrm{ccm}$ showed a lower friction coefficient than the film deposited at $f_{\mathrm{N}_{2}}=1.0 \mathrm{ccm}$. This may be because the Mo content of the film deposited at $f_{\mathrm{N}_{2}}=2.0 \mathrm{ccm}$ is higher than that at $f_{\mathrm{N}_{2}}=1.0 \mathrm{ccm}$, as shown in Table II. Although the reason for the difference in the Mo content is not clear at present, the Mo dependence is consistent with the results by Yang et al. ${ }^{[17]}$ They reported that the friction coefficient of Ti-Mo-N film decreased with an increase in the Mo content. ${ }^{[17]}$ Therefore, the lower friction coefficient of the film deposited at $f_{\mathrm{N}_{2}}=2.0 \mathrm{ccm}$ is caused by a higher Mo content that may produce a larger amount of fine particles of molybdenum oxide.

\section{CONCLUSIONS}

Ti-Mo-N films were deposited by reactive sputtering of a $\mathrm{Ti}_{50} \mathrm{Mo}_{50}$ alloy target with various nitrogen gas flow rate. The effects of the nitrogen content on the crystal structure, microstructure, and mechanical properties were investigated. The findings are summarized in the following list:

1. The Ti-Mo-N films had different crystalline phases with increasing nitrogen gas flow rate, $f_{\mathrm{N}_{2}}$; a bcc(Ti,Mo) phase with a $\varepsilon-\mathrm{Ti}_{2} \mathrm{~N}$ phase, a $\delta-(\mathrm{Ti}, \mathrm{Mo}) \mathrm{N}$ phase with a $\varepsilon-\mathrm{Ti}_{2} \mathrm{~N}$ phase, and a $\delta-(\mathrm{Ti}, \mathrm{Mo}) \mathrm{N}$ single phase.

2. Hardness drastically increased with increasing $f_{\mathrm{N}_{2}}$ in the initial stage and then slightly decreased after reaching a maximum hardness of approximately $30 \mathrm{GPa}$ at $f_{\mathrm{N}_{2}}=0.3 \mathrm{ccm}$ ( $\mathrm{N}$ content $\approx 37$ at. pct). Moreover, in the region of $f_{\mathrm{N}_{2}}>0.5 \mathrm{ccm}$, hardness showed approximately a constant value of about
$25 \mathrm{GPa}(\mathrm{N}$ content $\approx 42$ at. pct). The Ti-Mo-N film deposited at $f_{\mathrm{N}_{2}}=0.3 \mathrm{ccm}$ showed a maximum hardness that was obtained in the $\delta$-(Ti,Mo)N phase with the smallest grain size.

3. The friction coefficient of the Ti-Mo-N coating films decreased with increasing $f_{\mathrm{N}_{2}}$, because the size of wear debris became smaller with increasing $f_{\mathrm{N}_{2}}$. The Ti-Mo-N film at $f_{\mathrm{N}_{2}}=2.0 \mathrm{ccm}$ showed the lowest friction coefficient of 0.44 .

4. The Ti-Mo-N film with a high nitrogen content showed a well-balanced coating properties.

\section{ACKNOWLEDGMENT}

This work was supported in part by the Osawa Scientific Studies Grants Foundation.

\section{OPEN ACCESS}

This article is distributed under the terms of the Creative Commons Attribution Noncommercial License which permits any noncommercial use, distribution, and reproduction in any medium, provided the original author(s) and source are credited.

\section{REFERENCES}

1. H. Holleck: J. Vac. Sci. Technol. A, 1986, vol. 4, pp. 2661-69.

2. R.A. Andrievski, I.A. Anisimova, and V.P. Anisimov: Thin Solid Films, 1991, vol. 205, pp. 171-75.

3. W.D. Münz: J. Vac. Sci. Technol. A, 1986, vol. 4, pp. 2717-25.

4. O. Knotek, W.D. Münz, and T. Leyendecker: J. Vac. Sci. Technol. A, 1987, vol. 5, pp. 2173-79.

5. P.H. Mayrhofer, A. Hörling, L. Karlsson, J. Sjölén, T. Larsson, C. Mitterer, and L. Hultman: Appl. Phys. Lett., 2003, vol. 83, pp. 2049-51.

6. S. Vepřek, S. Reiprich, and Li. Shizhi: Appl. Phys. Lett., 1995, vol. 66 , pp. $2640-42$.

7. S. Vepřek and S. Reiprich: Thin Solid Films, 1995, vol. 268, pp. 64-71.

8. W. Gissler: Surf. Coat. Technol., 1994, vol. 68/69, pp. 556-63.

9. C. Mitterer, P.H. Mayrhofer, M. Beschliesser, P. Losbichler, P. Warbichler, F. Hofer, P.N. Gibson, W. Gissler, H. Hruby, J. Musil, and J. Vlček: Surf. Coat. Technol., 1999, vols. 120-121, pp. $405-11$

10. Y.H. Lu, Y.G. Shen, Z.F. Zhou, and K.Y. Li: Wear, 2007, vol. 262, pp. 1372-79.

11. Y.H. Lu, Z.-J. Liu, and Y.G. Shen: Acta Mater., 2006, vol. 54, pp. 2897-2905.

12. Z.P. Huang, Y. Sun, and T. Bell: Wear, 1994, vol. 173, pp. 13-20.

13. C.-L. Chang, C.-T. Lin, P.-C. Tsai, W.-Y. Ho, and D.-Y. Wang: Thin Solid Films, 2008, vol. 516, pp. 5324-29.

14. H.-S. Ahn, I.-W. Lyo, and D.-S. Lim: Surf. Coat. Technol., 2000, vols. 133-134, pp. 351-61.

15. M. Ürgen, O.L. Eryılmaz, A.F. Çukır, E.S. Kayali, B. Nilüfer, and Y. Işik: Surf. Coat. Technol., 1997, vols. 94-95, pp. 501-06.

16. P.J. Rudnik, M.E. Graham, and W.D. Sproul: Surf. Coat. Technol., 1991, vol. 49, pp. 293-97.

17. Q. Yang, L.R. Zhao, P.C. Patnaik, and X.T. Zeng: Wear, 2006, vol. 261, pp. 119-25.

18. F. Vaz, J. Ferreira, E. Ribeiro, L. Rebouta, S. Lanceros-Méndez, J.A. Mendes, E. Alves, Ph. Goudeau, J.P. Rivière, F. Ribeiro, 
I. Moutinho, K. Pischow, and J. de Rijk: Surf. Coat. Technol., 2005, vol. 191, pp. 317-23.

19. P.Y. Park, E. Akiyama, H. Habazaki, A. Kawashima, K. Asami, and K. Hashimoto: Corros. Sci., 1996, vol. 38, pp. 1649-67.

20. J.-E. Sundgen, B.-O. Johansson, S.-E. Karlsson, and H.T.G. Hentzell: Thin Solid Films, 1983, vol. 105, pp. 367-84.
21. S. Inoue, T. Ohba, H. Takata, and K. Koterazawa: Thin Solid Films, 1999, vols. 343-344, pp. 230-33.

22. T. Polcar, N.M.G. Parreira, and A. Cavaleiro: Wear, 2007, vol. 262 , pp. $655-65$.

23. B.-Y. Shew and J.-L. Huang: Surf. Coat. Technol., 1995, vol. 71, pp. 30-36. 